\title{
ODONTOLOGÍA EN LA UNIVERSIDAD NACIONAL AUTÓNOMA DE HONDURAS EN EL VALLE DE SULA
} Odontology in the Sula Valley National Autonomous University of Honduras

La Revista Científica de la Escuela Universitaria de las Ciencias de la Salud (EUCS) se complace en presentarles su segundo número. Como ya fue expresado en el primer número, la EUCS de la Universidad Nacional Autónoma de Honduras en el Valle de Sula (EUCS UNAH-VS), está constituida por tres carreras, de las cuales la primera en crearse fue enfermería, dedicándose la primera Revista a la historia de su creación. La segunda en surgir fue la Carrera de Odontología, razón por la cual se le dedica este segundo número. ${ }^{(1)}$

La historia de la odontología se remonta a por lo menos 5000 años antes de Cristo, se tienen evidencias que los egipcios por el año 3000 a.C. ya realizaban extracciones dentales y trepanaban la cortical externa de la mandíbula para drenar abscesos odontológicos, trataban inflamaciones bucales y reponían las piezas dentales ausentes con diferentes sistemas incluyendo piedras preciosas. Los arqueólogos sostienen que la incidencia de las caries en los egipcios era baja en el período antiguo y que se fue incrementando gradualmente a medida que la dieta se hizo más rica en hidratos de carbono.

Hipócrates (460 a 370 a.C.), fue un médico de la Antigua Grecia, quien fundo la Escuela Hipocrática, considerado el primer médico que rechazó las supersticiones, leyendas y creencias populares. Con Aristóteles, escribieron sobre ungüentos y procedimientos de esterilización usando un alambre caliente para tratar las enfermedades de los dientes y los tejidos orales, también sobre la extracción dental y el uso de alambres para estabilizar fracturas maxilares y soportar dientes ausentes.

Antes de la edad media, los tratamientos se fundamentaban en realizar extracciones dentales, fue en esta época que disminuyó esta práctica tratando de conservar las piezas dentales. Guy de Chauliac (1300-1368). Escribió la obra "Inventorium Chirurgicalis Medicinae" documento importante en que se analiza la anatomía de los dientes y su erupción. ${ }^{(2)}$

En Honduras, antes de la década de los 40 las prácticas odontológicas eran realizadas de forma empírica, fue a principio de 1940 cuando llegaron profesionales de la Odontología graduados en universidades extranjeras y fundaron la Asociación Dental Hondureña, entre ellos, los doctores; Lisandro Gálvez, Federico Smith, Adolfo Zavala, Fernando Marichal, Wilfredo Renaú, Felipe Lardizábal, Carlos Zepeda y Diderico Lazaruz.

Entre $1940-1950$ se inician las gestiones para formar profesionales de la Odontología en Honduras, iniciando a funcionar la Facultad de Odontología adscrita a la Facultad de Medicina. Siendo el Dr. Lazaruz presidente de la Asociación Dental Hondureña, quien solicita apoyo al Doctor Juan Manuel Gálvez entonces presidente de la República logrando la separación y el funcionamiento de esta carrera en Ciudad Universitaria el 11 de 
noviembre de 1949, según Acuerdo N. ${ }^{\circ} 369$ del Palacio Nacional.

La Facultad de Odontología surge como unidad académica dependiente de la Universidad Nacional Autónoma de Honduras el 3 de julio 1952. Siendo, el Doctor Lisandro Gálvez, su Decano y el Doctor Rainel Fúnez el primer estudiante en graduarse.

En San Pedro Sula, en la Universidad Nacional Autónoma de Honduras en el Valle de Sula UNAH-VS (en ese entonces, Centro Regional del Norte CURN) ante la creciente necesidad tanto de la población como de los estudiantes universitarios y después de muchos años de esfuerzo, el 24 de febrero del año 2000 siendo la Rectora la Dra. Ana Belén Castillo se inicia el proceso de apertura de la Carrera de Odontología, solicitando a la junta directiva de la Facultad de Odontología presidida por el Dr. Raúl Antonio Santos Maldonado en calidad de Decano se pronuncie, emitiendo dictamen con el fin de aprobar la creación de dicha carrera, creándose bajo el Acuerdo No. 014-2000-CUO del honorable Consejo Universitario. Luego pasa a formar parte de la EUCS/ UNAH-VS, desde su creación en el año 2008, según acuerdo No 348- A- 2008.

La creación de la Carrera de Odontología se traduce en bienestar para la población de la región noroccidental de nuestro país, con los aportes que brindan las clínicas odontológicas de la UNAH-VS, y con el trabajo de sus egresados tanto en clínicas estatales como privadas, lo que ha traído mejoría a la salud integral de la población. La salud bucal es de suma importancia para evitar pérdidas dentales, enfermedades sistémicas como por ejemplo abscesos endocárdicos, sobretodo en pacientes con patologías asociadas como cardiopatías, asimismo mantener la estética bucal y bienestar psicológico. También ha sido beneficiosa para los jóvenes que desean formarse en esta rama de la salud y sus padres pues ya no hay que viajar hasta otras ciudades o países para poder ser un profesional de la odontología. (3)

\section{Dra. Tania Soledad Licona Rivera}

Directora de la Revista tania.licona@unah.edu.hn

Recibido: 26 de Febrero 2,015 Aprobado 12 de Marzo 2,015

\section{BIBLIOGRAFÍA}

1. Tania Soledad Licona Rivera. La Ciencia de la Enfermería. Revista Científica de la Escuela Universitaria de las Ciencias de la Salud. 2014; 1 (1):3.

2. Propdental [internet]. España: Clínicas Propdental de Barcelona. [Citado 2015, 10 de marzo] Disponible en: https:// www.propdental.es/blog/odontologia/ historia-de-la-odontologia-en-la-antigua-grecial.
3. Cruz Fajardo EF. Historia de Odontología en la Universidad Nacional Autónoma de Honduras en el Valle de Sula. Revista Científica de la Escuela Universitaria de las Ciencias de la Salud. De próxima aparición 2014. 